\title{
How to Manage Small Intestine (Jejunal and lleal) Neuroendocrine Neoplasms Presenting with Liver Metastases?
}

\author{
Bruno Niederle $^{1} \cdot$ Andreas Selberherr $^{1} \cdot$ Martin B. Niederle $^{2}$ \\ Accepted: 31 March 2021 / Published online: 20 May 2021 \\ (C) The Author(s) 2021
}

\begin{abstract}
Purpose of Review Small intestinal neuroendocrine neoplasms (siNENs) are slowly growing tumours with a low malignant potential. However, more than half of the patients present with distant metastases (stage IV) and nearly all with locoregional lymph node (LN) metastases at the time of surgery. The value of locoregional treatment is discussed controversially.

Recent Findings In stage I to III disease, locoregional surgery was currently shown to be curative prolonging survival. In stage IV disease, surgery may prolong survival in selected patients with the chance to cure locoregional disease besides radical/debulking liver surgery. It may improve the quality of life and may prevent severe local complications resulting in a state of chronic malnutrition and severe intestinal ischaemia or bowel obstruction.

Summary Locoregional tumour resection offers the opportunity to be curative or to focus therapeutically on liver metastasis, facilitating various other therapeutic modalities. Risks and benefits of the surgical intervention need to be balanced individually.
\end{abstract}

Keywords Neuroendocrine tumour (neoplasm), Small bowel, Jejunum, Ileum, Locoregional surgery, Stage IV

\section{Introduction}

Neuroendocrine cells, distributed throughout the body and also diffusely scattered in the gastrointestinal (GI) tract, may give rise to neuroendocrine neoplasms (NENs). As demonstrated in a prospective, 1-year incidence study, 44 out of $306(14.4 \%)$ newly diagnosed gastro-entero-pancreatic NENs of the GI tract were located in the small intestine [1•].

This article is part of the Topical Collection on Neuroendocrine Neoplasms

Bruno Niederle

bruno.niederle@meduniwien.ac.at

Andreas Selberherr

andreas.selberherr@meduniwien.ac.at

Martin B. Niederle

martin.niederle@meduniwien.ac.at

1 Department of General Surgery, Divison of Visceral Surgery, Medical University of Vienna, Waehringer Gürtel 18-20, A-1090 Vienna, Austria

2 Department of Anaesthesia, Intensive Care Medicine and Pain Medicine, Medical University of Vienna, Waehringer Gürtel 18-20, A-1090 Vienna, Austria
Beside locations in the stomach (23\%) and appendix (21\%), the small bowel was seen to be the third most common site with an incidence of 0.29 per 100,000 inhabitants [1•].

Small intestinal NENs (SiNENs) are the most common type of small bowel malignancy and are diagnosed in 38 to $52 \%$ of all malignant tumours of the small bowel $[1 \bullet, 2]$.

\section{Background}

By definition, all NENs generally are malignant lesions, regardless of their location [3]. Following the oncologic principles, their malignant behaviour corresponds to the grading and TNM staging of the primary tumour at the time of diagnosis [4].

Although the majority of primary tumours were graded G1 $(37 \%)$ and G2 (63\%) [1•] and are therefore slow-growing lesions with an overall good prognosis, only a minority of patients presented with "localised disease" (WHO stage I/II; European Neuroendocrine Tumour Society [ENETS] I to IIIa: N0, M0 [16.1\%]) at the time of diagnosis. The majority was documented with lymph node (LN) metastasis ("regionalised" disease; WHO stage III; ENETS stage IIIb; N1, M0; [35.5\%]) or with "distant" metastasis (distant disease; WHO/ENETS stage IV, M1; [54.8\%]-Tables 1 and 2) [1•]. 
In a single-centre study, LN metastasis occurred in up to $93 \%$, and liver metastasis was revealed in $61 \%$ of the patients [5••]. Therefore, in more than half of the patients with siNENs, the treatment concepts are to focus not only on the primary tumour and its LN metastasis but also more intensively on distant metastasis, tumour-related symptoms and carcinoid heart disease, if present. Individualised multimodal treatment is to be discussed in interdisciplinary tumour boards to prolong survival [6]. Structured diagnostic and therapeutic algorithms are thus mandatory to select the individualised therapy with the highest chance to improve prognosis and quality of life (Tables 3 and 4).

\section{Aim}

This article deals with the treatment of the primary tumour and LN metastasis (locoregional disease) in patients with distant metastasis on the basis of international guidelines $[7 \bullet, 8 \bullet, 9 \bullet$, $10 \bullet, 11 \bullet, 12 \bullet]$ and recently published meta-analyses [13••, $14 \bullet \bullet, 15 \bullet \bullet, 16 \bullet \bullet$.

The current treatment concepts for resectable and nonresectable distant metastasis (peritoneal carcinomatosis [PC], liver) after successful (if possible, radical) treatment of

Table 1 TNM classification of small intestinal (si) neuroendocrine neoplasia (NEN)

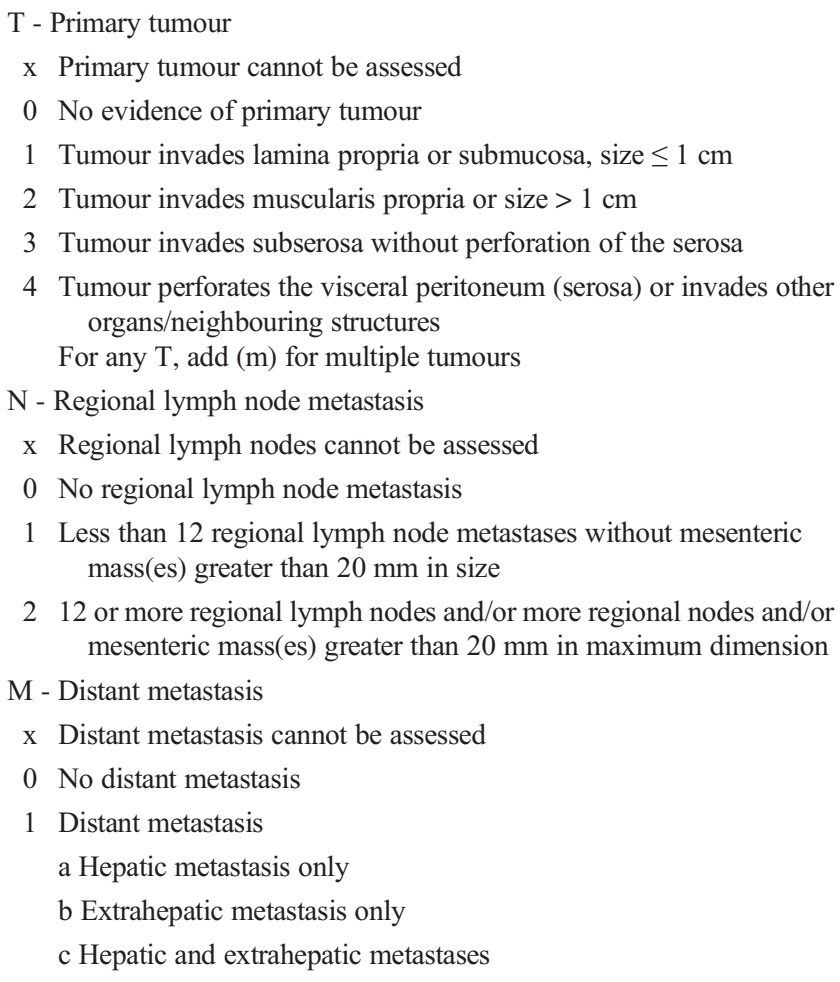

locoregional disease are not discussed in detail and are summarised elsewhere [17, 18, 19].

\section{Functionality}

SiNENs are non-functioning or functioning. The assessment of hormonal function is an important step in the diagnosis of the diseases and is induced when siNENs are suspected (Table 3). SiNENs secrete serotonin, and 5hydroxyindoleacetic acid (5-HIAA), a metabolite of serotonin, is excreted in the urine. Determining 5-HIAA levels in the 24-h urine collection is the most useful test in confirming the diagnosis of siNENs and "carcinoid syndrome". 5-HIAA values were significantly higher in patients with siNENs graded G2 and in patients with $25 \%$ of liver volume involvement $[20 \bullet, 21 \bullet]$.

In the majority of patients, functionality correlates with more advanced disease. It is found in up to $45 \%$ of patients and may be caused by LN and/or distant metastasis [22]. Serotonin and other cytokines released from the tumour cells may induce fibrosis, leading to carcinoid heart disease and abdominal fibrotic reactions (desmoplasia) [23•, 24].

The symptoms of hormone hypersecretion may be mild or severe, resulting in carcinoid crisis and carcinoid heart disease. Carcinoid heart disease characterised by plaque-like deposits of connective tissue cells leading to tricuspid valve dysfunction or even heart failure may influence patients' general health condition and may thus reduce the chances of extended surgery [25]. Carcinoid heart disease is to be excluded before deciding on treatment. Such therapy is challenging, warrants a multidisciplinary approach and can be medical or surgical, depending on the cardiac manifestations [26•].

If the diagnosis of siNENs is confirmed, all patients should routinely be put on long-acting somatostatin analogues (SSAs), which are antisecretory (and in long-term treatment, antiproliferative), in order to prevent an escalation of clinical symptoms during diagnostic work-up and subsequent treatment [27•].

\section{Symptoms and pathway of diagnosis}

The majority of siNENs are diagnosed incidentally when unspecific upper abdominal pain $(33 \%)$ or intestinal bleeding $(15 \%)$ leads to further examinations [28•].

More specific symptoms for siNENs may be diarrhoea (21\%) or flushing $(9 \%)$ as signs of serotonin overproduction. Partial (18\%) or total bowel obstruction of both functioning and non-functioning tumours may require emergent operative interventions [29]. However, all these symptoms are unspecific and may also be found in NENs located in other parts of the GI tract [28•]. 
Table 2 WHO 2019 and ENETS 2007 staging of siNEN and frequency of locoregional and distant disease $[1 \bullet, 44 \bullet, 75 \bullet \bullet, 76 \bullet \bullet]$

\begin{tabular}{|c|c|c|c|c|c|c|c|c|}
\hline \multicolumn{3}{|l|}{ WHO } & \multicolumn{3}{|c|}{ ENETS } & \multirow{2}{*}{$\begin{array}{l}\text { ENETS+WHO } \\
\text { M }\end{array}$} & \multirow[t]{2}{*}{$n(\%)$} & \multirow[t]{2}{*}{ Disease } \\
\hline Stage & $\mathrm{T}$ & $\mathrm{N}$ & Stage & $\mathrm{T}$ & $\mathrm{N}$ & & & \\
\hline & & & 0 & Tis & 0 & 0 & 0 & Local \\
\hline I & 1 & 0 & I & 1 & 0 & 0 & $2(6.5)$ & Local \\
\hline II & 2 & 0 & IIa & 2 & 0 & 0 & $1(3.2)$ & Local \\
\hline II & 3 & 0 & $\mathrm{IIb}$ & 3 & 0 & 0 & $2(6.5)$ & Local \\
\hline III & 4 & any $\mathrm{N}$ & IIIIa & 4 & 0 & 0 & 0 & Local \\
\hline III & any $\mathrm{T}$ & Any N & IIIb & any $\mathrm{T}$ & 1 & 0 & $11(35.5)$ & Regional \\
\hline IV & any $\mathrm{T}$ & any $\mathrm{N}$ & IV & any $\mathrm{T}$ & any $\mathrm{N}$ & M1 a-c & $15(48.4)$ & Distant \\
\hline
\end{tabular}

Diffuse upper abdominal pain frequently corresponds to liver metastasis and is described in 20 to $67 \%$ of patients with various GI NENs when abdominal ultrasound (US) or computed tomography $(\mathrm{CT})$ is initially performed for tumour "screening" (Table 3) [1•].

In some of these stage IV tumours, the type and location of the primary tumour may remain unknown even after extended, additionally performed cross-sectional imaging (e.g. MRI) or endoscopy of the upper and lower GI tract as the second and third steps of the investigation pathway.
As shown recently [30], the site of the primary NEN may be based on biopsy specimens of the liver applying a specific set of immunohistochemical markers. Positive staining for CDX2 was documented in $43(86 \%)$ and for serotonin in 45 (90\%) of 50 siNENs.

Liver biopsy not only confirms the NEN itself and helps to identify the tumour site of origin but also facilitates tumour grading (Table 3). Liver lesions are often of a higher grade than the primary or its local or regional LN metastasis [31].

Table 3 Diagnostic pathway in siNEN

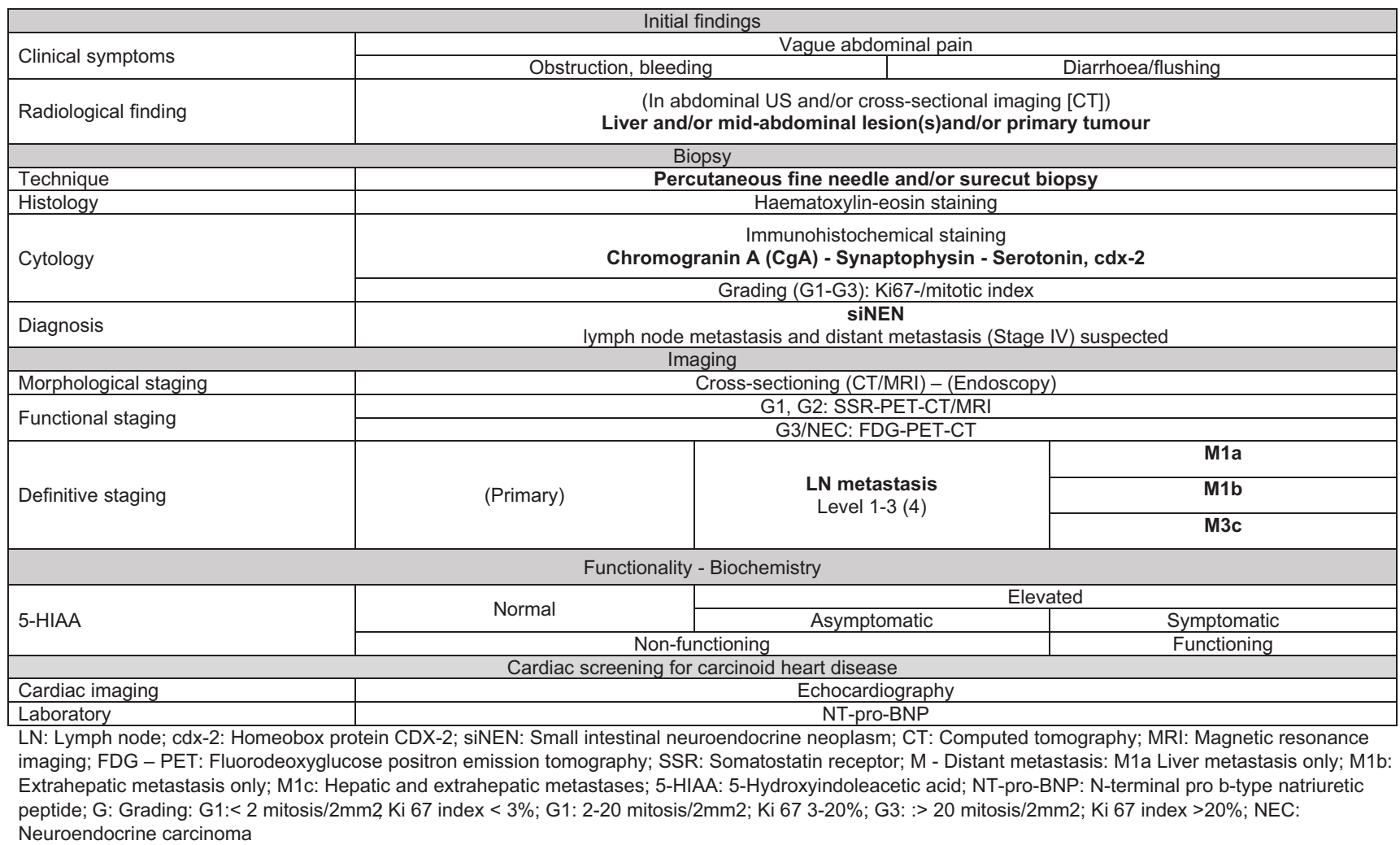


Table 4 Therapeutic pathways in siNEN Stage IV (pT1-4; pN1/2)

\begin{tabular}{llll}
\hline & M 1a & M1a-c & M1a-c \\
\hline Grading & G1-2 & G1-2 & G3/NEC \\
Surgical treatment & Radical resection curative intent & Palliative resection & NO resection \\
Surgical technique & Local radical open & Local radical open & Due to \\
T & Primary tumour(s) & Primary tumour(s) & Local ([T], N) inoperability \\
$\mathrm{N}$ & LN dissection & LN dissection & \\
& Levels 1-3 (4) & Levels 1-3 (4) & \\
$\mathrm{M}$ & Typical/atypical & Liver debulking - & Yes/no \\
Co-morbidity & Liver resection & Resection of PC & Palliation \\
Aim & no & no & \\
& Free from tumour & To avoid local complications by the tumour/LN metastasis & \\
& & (obstruction, bleeding, ischaemia) & \\
\end{tabular}

$L N$ Lymph node; $T$ Tumour, $N$ Node; $M$ - Distant metastasis M1a Liver metastasis only; $M 1 b$ Extrahepatic metastasis only; $M 1 c$ Hepatic and

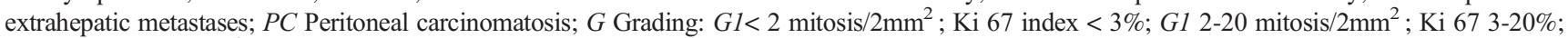
$G 3>20$ mitosis $/ 2 \mathrm{~mm}^{2}$; Ki 67 index $>20 \%$; NEC Neuroendocrine carcinoma

\section{Characteristics of siNENs}

\section{Primary tumours}

The majority of primary tumours are slowly growing submucosal lesions, only a few millimetres in size $(60 \% \leq 20 \mathrm{~mm})$, which invade the lamina propria or submucosa or the muscularis propria and are classified as pT1 or pT2 (Table 1). The lesions are more often located in the ileum (76\%) than in the distal jejunum $(24 \%)$ and may be multiple in up to $54 \%$ of cases $[32,33,34 \cdot, 35]$.

The verification of the primary in the small intestine is difficult and sometimes impossible with conventional radiological methods because of the per se invisible part of the bowel.

In more detailed investigations, contrast intestinal radiography, video capsule endoscopy, or double-balloon enteroscopy may be applied providing more information on the location and the number of lesions within the ileum and/or jejunum $[36,37]$.

CT enteroclysis appears to be inferior to video capsule enteroscopy (sensitivity and specificity: 50 and $25 \%$ vs. 38 and $100 \%$, respectively) [38].

However, the latter endoscopic diagnostic modalities are not widely available. They may be effective but are time-consuming and expensive. Their role in routine staging before planning treatment must require clearer definition, whilst from the practical point of view, they seem to be of minor importance $[39,40]$.

\section{LN metastasis}

Very early in the course of the disease, mesenteric LNs metastases are invariably involved as single or multiple metastases, regardless of the size of the primary tumours, and are verified in up to $88 \%$ along the superior mesenteric vessels $[35,41]$. LN metastasis were documented in even $46.9 \%$ of patients with siNENs $<10 \mathrm{~mm}[42 \bullet]$.

Extra-abdominal LN metastases were observed in 24 $(4.0 \%)$ of all patients at diagnosis and 37 (6.1\%) patients displayed extra-abdominal metastases (other than metastatic LNs) at diagnosis [5••].

Whilst primary tumours are rarely visualised on CT, mesenteric LN metastases typically and often appear as contrastenhancing soft-tissue masses with fibrotic bands radiating outward into the mesenteric fat in a stellate pattern surrounding $\mathrm{LN}$ metastasis [43•].

LN metastasis tends to develop a "desmoplastic stromal reaction", which is the result of coordinated changes in several stromal cells under the control of a single gene product, the CD36 protein. The repression of CD36 leads to a decrease in fat accumulation and an increase in matrix deposition [43•].

Obliterative processes with considerable variation in the degree and rate of progression of "desmoplasia" may cause vascular encasement. Clinically, this may lead to abdominal pain, disabling diarrhoea, weight loss to the extent of malnutrition and eventually the risk of life-threatening situations with acute intestinal obstruction or intestinal gangrene.

The current TNM classification (Table 1) subdivides patients with pathological (p) N1 and pN2 LN involvement [44••].

In the current pathological LN classification stage, $\mathrm{pN} 1$ by definition includes those patients with less than 12 regional LNs affected without mesenteric mass(es) greater than $20 \mathrm{~mm}$ in size. Patients with 12 or more positive regional nodes and/ 
or mesenteric mass(es) greater than $20 \mathrm{~mm}$ in maximum dimension are defined as $\mathrm{pN} 2$. The number of involved LNs is of prognostic relevance [45].

The number of resected and histopathologically examined and involved LNs and the LN ratios (involved nodes:total nodes) was prognostic for overall survival - patients with 12 or more resected and examined LNs had the best survival outcomes [46].

A lower metastatic node ratio predicted improved survival on multivariable analysis and is associated with high-volume institutions which are more experienced in LN dissection [42•].

The WHO classification is not helpful in clarifying the possibility of radical LN dissection, an important step in treatment decision-making. The neighbourhood of the LN bulk and possible vascular involvement are to be assessed by CT/ magnetic resonance imaging (MRI) angiography (coronal and sagittal view).

Ohrvall et al. [47••] proposed a surgical "LN staging (=level) classification" by evaluating the operability of primary and mesenteric LN metastases. LN involvement level 1 consists of tumours located close to the intestine, whilstLN level 2 tumours involve arterial branches near their origin in the mesenteric artery. Level 3 LN tumours extend along (without encircling) the superior mesenteric artery trunk, and level 4 LN metastases extend retroperitoneally, behind or above the pancreas, or grow around the mesenteric artery and involve the origin of proximal jejunal arteries on the left side of the superior mesenteric artery.

In their series [47••], $24 \%$ of 56 patients were surgically staged LN level 1, 22\% staged level 2, 28\% staged level 3 and $16 \%$ staged level 4. Level 4 LN tumours involved more proximal parts of the mesenteric artery, sometimes growing circumferentially around this vessel, and were not removable.

These findings were confirmed by Lardière-Deguelte et al. [48] who retrospectively analysed morphological imaging, consisting of early arterial-phase contrast-enhanced abdominal-pelvic CT and/or MRI, in an attempt to develop criteria to prospectively predict the operability of mesenteric LNs.

A key issue in siNEN resection is not necessarily the primary tumour itself. Surgery is to focus on preserving bowel function whilst selectively resecting mesenteric LNs. LN metastases have to be removed by cautious dissection around the superior mesenteric vessels in order to preserve the vascular supply to the small intestine and thus to avoid overextensive bowel resections. LN dissection along the vessels may be technically challenging, especially in complex situations with level and LN involvement. An appropriate preoperative LN cartography with respect to the jejunal vascular collaterals along the superior mesenteric vessels could help to estimate the technical demand of surgery. Radical lymphadenectomy along the superior mesenteric vessels may not necessarily require extended small bowel resection, which may cause "short bowel syndrome" and compromise patients' quality of life [48, 49••].

Skip metastases (LN metastases outside the "expected" lymphatic drainage) may occur in up to two thirds of patients, which may mandate more extensive lymphadenectomy to prevent unresectable locoregional recurrence [50].

Patients with local tumour-related symptoms generally undergo local resection at the time of diagnosis. However, some symptomatic patients have advanced level 4 LN metastases, encasing the superior mesenteric vessels and rendering radical resection challenging. In highly advanced situations including the infeasibility to remove the LN bulk with an acceptable level of morbidity, stenting and other palliative methods improve the clinical symptoms and prevent bowel ischaemia [51].

\section{Distant metastasis}

The liver and the peritoneum are the two most common distant metastatic sites. With regard to the site of distant metastasis [52], 80/219 (36.5\%) patients presented with hepatic metastasis only (M1a), $14(6.39 \%)$ with peritoneal metastasis only (M1b), and 53 (24.2\%) with both hepatic and peritoneal metastases (M1c) at the time of surgery or during follow-up, whilst $71(32.4 \%)$ patients were classified as M0.

Solitary liver metastases are the exception. In only 1 of 40 patients, a solitary liver lesion with curative outcome after resection was documented [35].

The majority of liver metastasis is multiple and often less than $10 \mathrm{~mm}$ in diameter. Because of their typical bilobar growth pattern, many resections of hepatic metastatic NENs that are considered curative at the time of surgery are palliative [35].

At the time of initial diagnosis, fewer than five metastases in one lobe were revealed in $80(21.9 \%)$ of 366 patients, 105 (28.7\%) patients had bilobar and/or 5 to 10 metastases and $139(38.0 \%)$ patients had more than 10 liver metastases, respectively. Ninety-nine (42\%) patients without liver metastases at initial diagnosis developed liver metastases during follow-up [5••].

Morphologically, three different patterns of liver infiltration by metastasis are to be differentiated, since they have an impact on the therapeutic approach $[19,53 \bullet]$ : in the "simple pattern" ([A]; type 1 ), the metastases correspond to a single metastasis or to metastases confined to one liver lobe or are limited to two adjacent segments so that they can be treated with a standard anatomical resection. In the "complex pattern" ([B]; type 2), there is one major focus (metastatic bulk) with accompanying smaller deposits contralaterally. Diffuse, multifocally disseminated metastatic spread involves all parts of the liver ([C]; type 3). Analysing patients with siNENs and 
liver metastasis, 5 (14.3\%) of 35 were classified as type 1,8 $(22.9 \%)$ as type 2 , and $22(62.9 \%)$ as type 3 , respectively.

A bilobar pattern can still be approached surgically when 70 to $90 \%$ of the metastasis can be removed (cytoreduction/ debulking) [53•, 54]. However, only up to $20 \%$ of patients may be candidates for surgery [53•].

Besides liver metastases in $48(57.1 \%)$ of 84 patients, solely peritoneal and bone metastases were observed in $2(2.4 \%)$ and $1(1.2 \%)$ patients, respectively [41].

Ovarian metastases occur in $4 \%$ of patients (potentially causing carcinoid syndrome) followed by pancreatic $(0.5 \%)$ and splenic metastases $(0.5 \%)$ [5••].

The presence of carcinoid heart disease and mesenteric LN metastases, distant abdominal LN metastases, liver metastatic burden, extra-abdominal metastases, skeletal involvement and $\mathrm{PC}$ are independent prognostic factors for overall survival in siNENs [5••]. Bone metastases are prognostically relevant [55].

Although occurring in only approximately 5\%, lung metastases may impact patients' outcome. The development of metachronous lung metastasis is associated with concomitant disease progression in established abdominal metastasis in most patients [56].

\section{Staging of the disease}

The specific oncological characteristics of siNENs emphasise the necessity of exact (T)NM staging prior to planning further treatment. This is the prerequisite before selecting any treatment regime.

In general, routine morphological radiological imaging techniques (abdominal US, CT, magnetic resonance tomography $[\mathrm{MRT}])$ tend to significantly underestimate the neuroendocrine disease [57].

Preoperative morphological imaging "understaged" the disease in 14/20 (70\%) when compared with intraoperative findings. In patients with multifocal primary tumours and miliary liver metastasis, no imaging modality was able to detect the entire extent of disease spread [41].

The currently preferred hybrid imaging method combines the advantage of $\mathrm{CT}$ or MR and SSA receptor imaging in demonstrating the anatomical/morphological details of a lesion and its functional characteristics. The further development of radioactively labelled derivatives of synthetic SSA and the improvement of positron emission tomography (PET) technology, with greater resolution and simultaneous specific binding of radiopharmaceuticals to various somatostatin (SS) receptor subtypes, have improved the staging of siNENs compared to SS receptor scintigraphy alone.

${ }^{68} \mathrm{Ga}$-DOTA-SSA PET/CT or MRT is recommended for functioning imaging in G1 and G2 tumours. This technique facilitates the diagnosis and extent of LN and distant metastases, such as peritoneal, liver and bone lesions [58].
Whole-body scans enable more exact staging and also the diagnosis of primaries in up to $89 \%$ of cases [59].

${ }^{18}$ FDG-PET/CT is better suited for G3 tumours, which generally have a higher level of glucose metabolism and less SS receptor expression than low-grade NENs, and additionally provides prognostic information.

However, single "hot spots" in functional imaging do not exclude multicentric disease. Therefore, if surgery is indicated, meticulous intraoperative abdominal examination with bidigital exploration of the small bowel, the liver and the abdominal cavity is to be performed as palpation is superior to any imaging technology [59].

Differences in preoperative hybrid imaging and intraoperative findings may influence the surgical strategy.

\section{Treatment of the primary siNEN and LN metastasis (N1/2) in patients with (M1) and without (M0) distant metastasis}

Positive LNs and distant metastasis in preoperative imaging do not per se exclude patients from surgery if they are fit for such treatment (heart disease not present or treated efficiently), and the siNEN itself or the distant metastasis is graded as $\mathrm{G} 1 / \mathrm{G} 2[60 \bullet \cdot$.

Traditionally, the approach of choice is laparotomy with meticulous exploration of the entire abdominal cavity excluding or verifying small extrahepatic metastasis with bidigital small bowel palpation to exclude multifocality and to determine the exact anatomy of LN metastasis to the superior mesenteric vessels [61].

Laparoscopic procedures with the intention of curative surgery remain controversial $[7 \bullet, 41,62]$. The level of evidence of the role of laparoscopic surgery for si-NENs is low. Laparoscopic techniques are feasible and safe and may be considered, provided that oncological surgical standards in treating siNENs are achieved. However, patients with highgrade mesenteric infiltration and multiple tumours do not seem to be optimal candidates for extended laparoscopic LN dissection.

In palliative intent, the laparoscopic approach seems to be advantageous for the resection of local disease in patients with unresectable LN and liver metastases [61].

\section{Arguments for locoregional surgery}

Although primary siNENs may have an indolent clinical local course for a long time, radical locoregional surgery should be discussed in all patients with locoregional siNENs, with or without distant metastasis, who fulfil the basic criteria $[6,7 \bullet$, $9 \cdot, 10 \bullet, 63,64]$.

The aim of locoregional prophylactic surgery in M0 and M1 patients is to improve quality of life by averting abdominal complications caused by unpredictable progressive local 
tumour growth which may ultimately result in bowel obstruction with the consequence of emergency surgery. Growing LN metastasis with fibrosis around the main vessels may result in a state of chronic malnutrition and severe intestinal ischaemia. These life-threatening local complications can be avoided by LN dissection as long as only LN levels 1 to 3 are affected [24, $65 \bullet \cdot]$.

Depending on the location and number of the primaries, the optimal surgical treatment consists of sparing segmental small bowel or ileocaecal resection (for distal ileal tumours) with dissection of the regional LNs along the superior mesenteric vessels up to the inferior border of the pancreas (stage $=$ levels 1 to $3[4])$.

\section{M0}

In patients with stage I to III disease, resection of the primary tumour and regional lymphadenectomy is indicated as a curative procedure which improves survival [66•].

In patients with radically removed positive LNs (pN1M0), the 1-, 5- and 10-year survival rates were 100\%, 100\% and 83 $\pm 15 \%$, respectively [35].

The completeness of LN dissection also influences prognosis. Both overall survival and relative survival were significantly improved in the patients whose metastatic mesenteric LNs were grossly radically removed (R0) as compared to those with remaining pathological mesenteric LNs (R1) [5••].

After curative surgery, there is no indication for specific medical treatment, and there is no proven role for neoadjuvant or adjuvant medical treatment in si-NEN patients.

\section{M1}

Surgery is recommended in selected patients in the "simple (type 1) pattern" of liver involvement with the chance to cure locoregional disease alongside synchronously performed radical liver surgery.

In stage IV disease with complex (type 2 or 3 ) liver involvement or unresectable extrahepatic distant metastasis, locoregional surgery is indicated in locally symptomatic patients $[8 \bullet]$.

Generally not considered to be curative, the value of locoregional surgery in asymptomatic patients is discussed controversially. After propensity score matching patients with and without prophylactic locoregional resection, Daskalakis et al. found no survival benefit comparing the two groups $[67 \bullet \bullet]$.

The first systematic review of the literature described a clear trend towards improved survival after resection [14••].

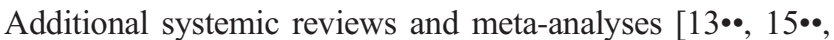
16*0] support the results authored by Capurso et al., demonstrating that palliative resection of primary siNENs in the setting of unresectable metastatic disease may improve survival.
The results of all the reviews and meta-analyses must be interpreted with caution due to potential selection and publication bias. The data support the consideration of surgery, particularly in patients with low tumour load and good functional status.

Because large, randomised prospective studies investigating the management of primary tumour and regional LN metastasis in association with liver metastases are lacking, the optimal treatment strategy remains debatable and should be discussed individually in multidisciplinary tumour boards.

Resection of liver metastasis may improve survival $[68,69$, $70,71,72,73]$ with a 10 -year survival rate of approx. 50 to $60 \%$ in patients having undergone either surgical resection or ablation of liver metastases. However, the cure rates are low and recurrence in the liver is frequent.

Factors influencing prognosis are unclear. Manguso et al. [74•] recently evaluated how the extent of liver resection (complete resection ([CR], partial resection [PR], or no resection [NR]) influences outcomes after complete resection of the primary tumour.

The 5-year rate of overall survival was $79.4 \%$ for NR, $84.7 \%$ for PR and $100 \%$ for CR, demonstrating a trend that $\mathrm{CR}$ was the best, followed by PR then NR. However, 10-year overall survival showed no significant differences $(72.7 \%$ NR; $84.7 \%$ PR; $82.5 \%$ CR). More than 10 liver lesions or receiving chemotherapy were negative predictors of survival.

The minimal criteria required for liver surgery with "curative intent" are resectable G1/G2 liver disease with acceptable levels of morbidity $(<20 \%)$ and mortality $(<5 \%)$, the absence of right heart insufficiency and of extra-abdominal metastases (previously assessed by hybrid imaging), the absence of diffuse PC and a locoregionally resectable or already resected tumour.

Locoregional resection performed by an experienced surgical team following a standardised surgical technique with low morbidity and mortality [48] has the objective to make unresectable liver metastases the only persisting problem. The selective treatment of the liver by various ablative therapies may improve overall prognosis [18].

With regard to peritoneal metastases, surgical resection is recommended synchronously with the primary tumour, LN and hepatic metastasis, if feasible, to control symptoms [7•, 64].

\section{Conclusion}

In stage I to III disease, locoregional surgery may be curative. In stage IV disease, surgery is recommended in selected patients with the chance to cure locoregional disease besides radical liver surgery in the "simple (type 1) pattern" of liver involvement. In stage IV disease with complex (type 2 or 3) liver involvement or unresectable extrahepatic distant metastasis, locoregional surgery is indicated in locally symptomatic patients. Resection of the primary tumour should also be 
attempted in locally asymptomatic patients as the overall outcome may be better in patients after primary tumour resection even with distant metastasis although a direct causal relationship has not been proven to date. The type of surgery should be individualised, and no general approach can be recommended. The risks and benefits of the surgical intervention and the merits of pharmacological treatment (e.g. SSAs) have to be balanced. As such, the treatment of such patients is driven primarily by surgeons' experience, and available data are based predominantly on retrospective studies. Keeping this in mind, current recommendations advocate for patients with siNENs (localised or metastatic) to be managed by multidisciplinary teams in experienced centres.

Funding Open access funding provided by Medical University of Vienna.

\section{Compliance with Ethical Standards}

This paper is not based on a previous communication to a society or a meeting.

Conflict of Interest Bruno Niederle, Andreas Selberherr, and Martin B. Niederle declare that they have no conflict of interest.

Human and Animal Rights and Informed Consent For all trials performed by the authors informed consent for all diagnostic and therapeutic procedures was obtained from each patient, adhering to the Declaration of Helsinki. The Ethics Committee of the Medical University of Vienna confirmed all diagnostic and therapeutic protocols).

Open Access This article is licensed under a Creative Commons Attribution 4.0 International License, which permits use, sharing, adaptation, distribution and reproduction in any medium or format, as long as you give appropriate credit to the original author(s) and the source, provide a link to the Creative Commons licence, and indicate if changes were made. The images or other third party material in this article are included in the article's Creative Commons licence, unless indicated otherwise in a credit line to the material. If material is not included in the article's Creative Commons licence and your intended use is not permitted by statutory regulation or exceeds the permitted use, you will need to obtain permission directly from the copyright holder. To view a copy of this licence, visit http://creativecommons.org/licenses/by/4.0/.

\section{References}

Papers of particular interest, published recently, have been highlighted as:

- Of importance

•. Of major importance

1. Niederle MB, Hackl M, Kaserer K, Niederle B. Gastroenteropancreatic neuroendocrine tumours: the current incidence and staging based on the WHO and European Neuroendocrine Tumour Society classification: an analysis based on prospectively collected parameters. Endocr Relat Cancer. 2010;17(4):909-18. https://doi.org/10.1677/ERC-10-0152 NENs of the digestive tract are more common than previously reported; the majority show benign behaviour, are located in the stomach and are well differentiated. G3 tumours are very rare.

2. Bilimoria KY, Bentrem DJ, Wayne JD, Ko CY, Bennett CL, Talamonti MS. Small bowel cancer in the United States: changes in epidemiology, treatment, and survival over the last 20 years. Ann Surg. 2009;249(1):63-71. https://doi.org/10.1097/SLA. 0b013e31818e4641.

3. Kloppel G, Rindi G, Anlauf M, Perren A, Komminoth P. Sitespecific biology and pathology of gastroenteropancreatic neuroendocrine tumors. Virchows Arch. 2007;451(Suppl 1):S9-27. https:// doi.org/10.1007/s00428-007-0461-0.

4. Sun Y, Lohse C, Smyrk T, Hobday T, Kroneman T, Zhang L. The influence of tumor stage on the prognostic value of Ki-67 index and mitotic count in small intestinal neuroendocrine tumors. Am J Surg Pathol. 2018;42(2):247-55. https://doi.org/10.1097/PAS. 0000000000000968.

5.• Norlen O, Stalberg P, Oberg K, Eriksson J, Hedberg J, Hessman O, et al. Long-term results of surgery for small intestinal neuroendocrine tumors at a tertiary referral center. World J Surg. 2012;36(6): 1419-31. https://doi.org/10.1007/s00268-011-1296-z Locoregional removal of the primary tumor/mesenteric lymph node metastases was a positive prognostic factor by crude and adjusted analysis and may influence survival.

6. Pavel M, O'Toole D, Costa F, Capdevila J, Gross D, Kianmanesh $\mathrm{R}$, et al. ENETS Consensus Guidelines Update for the management of distant metastatic disease of intestinal, pancreatic, bronchial neuroendocrine neoplasms (NEN) and NEN of unknown primary site. Neuroendocrinology. 2016;103(2):172-85. https://doi.org/10. $1159 / 000443167$

7. Howe JR, Cardona K, Fraker DL, Kebebew E, Untch BR, Wang YZ, et al. The surgical management of small bowel neuroendocrine tumors: consensus Guidelines of the North American Neuroendocrine Tumor Society. Pancreas. 2017;46(6):715-31. https://doi.org/10.1097/MPA.0000000000000846 Consensus Guidelines of the North American Neuroendocrine Tumor Society.

8. Network NCC. NCCN Clinical Practice Guidelines in Oncology neuroendocrine and adrenal tumors. 2020. NCCN Clinical Practice Guidelines Neuroendocrine Tumors

9. Niederle B, Pape UF, Costa F, Gross D, Kelestimur F, Knigge U, et al. ENETS Consensus Guidelines Update for neuroendocrine neoplasms of the jejunum and ileum. Neuroendocrinology. 2016;103(2):125-38. https://doi.org/10.1159/000443170 ENETS Consensus Guidelines Update for neuroendocrine neoplasms of the jejunum and ileum.

10. Singh S, Asa SL, Dey C, Kennecke H, Laidley D, Law C, et al. Diagnosis and management of gastrointestinal neuroendocrine tumors: an evidence-based Canadian consensus. Cancer Treat Rev. 2016;47:32-45. https://doi.org/10.1016/j.ctrv.2016.05.003. Canadian consensus recommendations to guide state of the art clinical management of gastro-intestinal neuroendocrine tumors.

11. Oberg K, Knigge U, Kwekkeboom D, Perren A, Group EGW. Neuroendocrine gastro-entero-pancreatic tumors: ESMO Clinical Practice Guidelines for diagnosis, treatment and follow-up. Ann Oncol. 2012;23(Suppl 7:vii124-30). https://doi.org/10.1093/ annonc/mds295 ESMO Clinical Practice Guidelines for diagnosis, treatment and follow-up neuroendocrine gastroentero-pancreatic tumors.

12. Ramage JK, Davies AH, Ardill J, Bax N, Caplin M, Grossman A, et al. Guidelines for the management of gastroenteropancreatic neuroendocrine (including carcinoid) tumours. Gut. 2005;54(Suppl 4: iv1-16). https://doi.org/10.1136/gut.2004.053314 UKNET 
guidelines for the management of gastroenteropancreatic neuroendocrine tumours.

13.• Almond LM, Hodson J, Ford SJ, Gourevitch D, Roberts KJ, Shah $\mathrm{T}$, et al. Role of palliative resection of the primary tumour in advanced pancreatic and small intestinal neuroendocrine tumours: a systematic review and meta-analysis. Eur J Surg Oncol. 2017;43(10):1808-15. https://doi.org/10.1016/j.ejso.2017.05.016 Meta-analysis demonstrates that palliative resection of primary SI-NETs in the setting of unresectable metastatic disease can increase survival.

14.• Capurso G, Rinzivillo M, Bettini R, Boninsegna L, Delle Fave G, Falconi M. Systematic review of resection of primary midgut carcinoid tumour in patients with unresectable liver metastases. Br J Surg. 2012;99(11):1480-6. https://doi.org/10.1002/bjs.8842 Available data suggest a possible benefit of resection of the primary lesion in patients with unresectable liver metastases, but the studies have several limitations and the results should therefore be considered with caution.

15.• Guo J, Zhang Q, Bi X, Zhou J, Li Z, Huang Z, et al. Systematic review of resecting primary tumor in MNETs patients with unresectable liver metastases. Oncotarget. 2017;8((10):17396405. https://doi.org/10.18632/oncotarget.14156 Current evidence supports resection of primary tumor for midgut neuroendocrine tumor patients with liver metastases, but randomized controlled trials are required to reach a final conclusion.

16.• Tsilimigras DI, Ntanasis-Stathopoulos I, Kostakis ID, Moris D, Schizas D, Cloyd JM, et al. Is resection of primary midgut neuroendocrine tumors in patients with unresectable metastatic liver disease justified? A systematic review and meta-analysis. J Gastrointest Surg. 2019;23(5):1044-54. https://doi.org/10.1007/ s11605-018-04094-9 Primary tumor resection was safe with a low peri-operative risk of mortality and was associated with an improved overal survival for patients with midgut neuroendocrine tumors and unresectable liver metastases. Given the poor quality of evidence, however, strong evidenced-based recommendations cannot be made based on these retrospective single-centre-derived data. Future well-design randomized controlled trials will be critical in elucidating the optimal treatment strategies for patients with MNET and advanced metastatic disease.

17. Norlen O, Edfeldt K, Akerstrom G, Westin G, Hellman P, Bjorklund $\mathrm{P}$, et al. Peritoneal carcinomatosis from small intestinal neuroendocrine tumors: clinical course and genetic profiling. Surgery. 2014;156(6):1512-21; discussion 21-2. https://doi.org/ 10.1016/j.surg.2014.08.090.

18. Pavel M, Baudin E, Couvelard A, Krenning E, Oberg K, Steinmuller T, et al. ENETS Consensus Guidelines for the management of patients with liver and other distant metastases from neuroendocrine neoplasms of foregut, midgut, hindgut, and unknown primary. Neuroendocrinology. 2012;95(2):157-76. https:// doi.org/10.1159/000335597.

19. Steinmuller T, Kianmanesh R, Falconi M, Scarpa A, Taal B, Kwekkeboom DJ, et al. Consensus guidelines for the management of patients with liver metastases from digestive (neuro)endocrine tumors: foregut, midgut, hindgut, and unknown primary. Neuroendocrinology. 2008;87(1):47-62. https://doi.org/10.1159/ 000111037.

20. Gut P, Ruchala M. Evaluation of 5-hydroxyindoloacetic acid excretion in urine in patients with small intestine neuroendocrine neoplasm and carcinoid syndrome treated with somatostatin analogues. Neuro Endocrinol Lett. 2019;40(7-8):315-8 Assessment of 5HIAA excretion in patients with carcinoid syndrome is of considerable significance in the diagnostics and monitoring of the treatment.
21. Laskaratos FM, Diamantopoulos L, Walker M, Walton H, Khalifa M, El-Khouly F, et al. Prognostic factors for survival among patients with small bowel neuroendocrine tumours associated with mesenteric desmoplasia. Neuroendocrinology. 2018;106(4):36680. https://doi.org/10.1159/000486097 This study is the first comprehensive survival analysis of patients with SI NETs associated with mesenteric desmoplasia and has provided important and clinically relevant epidemiological data for this group of patients.

22. Hellman P, Lundstrom T, Ohrvall U, Eriksson B, Skogseid B, Oberg K, et al. Effect of surgery on the outcome of midgut carcinoid disease with lymph node and liver metastases. World J Surg. 2002;26(8):991-7. https://doi.org/10.1007/s00268-002-6630-z.

23. Clement D, Ramage J, Srirajaskanthan R. Update on pathophysiology, treatment, and complications of carcinoid syndrome. J Oncol. 2020;2020:8341426. https://doi.org/10.1155/2020/8341426 Carcinoid crisis is a life-threatening complication of CS which can appear spontaneously but mostly described during surgery, anaesthesia, chemotherapy, PRRT, and radiological procedures and may be prevented by octreotide administration.

24. Daskalakis K, Karakatsanis A, Stalberg P, Norlen O, Hellman P. Clinical signs of fibrosis in small intestinal neuroendocrine tumours. Br J Surg. 2017;104(1):69-75. https://doi.org/10.1002/bjs. 10333.

25. Hassan SA, Banchs J, Iliescu C, Dasari A, Lopez-Mattei J, Yusuf SW. Carcinoid heart disease. Heart. 2017;103(19):1488-95. https:// doi.org/10.1136/heartjnl-2017-311261.

26. Ram P, Penalver JL, Lo KBU, Rangaswami J, Pressman GS. Carcinoid heart disease: review of current knowledge. Tex Heart Inst J. 2019;46(1):21-7. https://doi.org/10.14503/THIJ-17-6562 The review covers the current knowledge about the pathophysiology, diagnosis, and treatment of carcinoid heart disease.

27. Stueven AK, Kayser A, Wetz C, Amthauer H, Wree A, Tacke F, et al. Somatostatin analogues in the treatment of neuroendocrine tumors: past, present and future. Int J Mol Sci. 2019;20(12). https://doi.org/10.3390/ijms20123049 The review highlights the clinical evidence of SSAs in monotherapy, and in combination with other treatment modalities, as applied to the antiproliferative management of neuroendocrine tumors with special attention to recent high-quality phase III trials.

28. Niederle MB, Niederle B. Diagnosis and treatment of gastroenteropancreatic neuroendocrine tumors: current data on a prospectively collected, retrospectively analyzed clinical multicenter investigation. Oncologist. 2011;16(5):602-13. https://doi.org/ 10.1634/theoncologist.2011-0002 This investigation summarizes the prospectively collected clinical presentation and current practice of management of GEP-NETs and thereby extends the understanding and clinical experience.

29. Manguso N, Gangi A, Nissen N, Harit A, Siegel E, Hendifar A, et al. Long-term outcomes after elective versus emergency surgery for small bowel neuroendocrine tumors. Am Surg. 2018;84(10): $1570-4$.

30. Selberherr A, Koperek O, Riss P, Scheuba C, Kaderli R, Perren A, et al. Neuroendocrine liver metastasis-a specific set of markers to detect primary tumor sites. Endocr Pathol. 2019;30(1):31-4. https:// doi.org/10.1007/s12022-018-9558-z.

31. Koo J, Dhall D. Problems with the diagnosis of metastatic neuroendocrine neoplasms. Which diagnostic criteria should we use to determine tumor origin and help guide therapy? Semin Diagn Pathol. 2015;32(6):456-68. https://doi.org/10.1053/j.semdp.2015. 09.013.

32. Choi AB, Maxwell JE, Keck KJ, Bellizzi AJ, Dillon JS, O'Dorisio $\mathrm{TM}$, et al. Is multifocality an indicator of aggressive behavior in small bowel neuroendocrine tumors? Pancreas. 2017;46(9):111520. https://doi.org/10.1097/MPA.0000000000000911. 
33. Gangi A, Siegel E, Barmparas G, Lo S, Jamil LH, Hendifar A, et al. Multifocality in small bowel neuroendocrine tumors. J Gastrointest Surg. 2018;22(2):303-9. https://doi.org/10.1007/s11605-0173586-8.

34. Keck KJ, Maxwell JE, Utria AF, Bellizzi AM, Dillon JS, O'Dorisio $\mathrm{TM}$, et al. The distal predilection of small bowel neuroendocrine tumors. Ann Surg Oncol. 2018;25(11):3207-13. https://doi.org/10. 1245/s10434-018-6676-2 SBNETs are frequently multifocal and most commonly located within $100 \mathrm{~cm}$ of the ileocecal valve.

35. Schindl M, Kaczirek K, Passler C, Kaserer K, Prager G, Scheuba C, et al. Treatment of small intestinal neuroendocrine tumors: is an extended multimodal approach justified? World J Surg. 2002;26(8):976-84. https://doi.org/10.1007/s00268-002-6628-6.

36. Bailey AA, Debinski HS, Appleyard MN, Remedios ML, Hooper JE, Walsh AJ, et al. Diagnosis and outcome of small bowel tumors found by capsule endoscopy: a three-center Australian experience. Am J Gastroenterol. 2006;101(10):2237-43. https://doi.org/10. 1111/j.1572-0241.2006.00749.x.

37. Bellutti M, Fry LC, Schmitt J, Seemann M, Klose S, Malfertheiner $\mathrm{P}$, et al. Detection of neuroendocrine tumors of the small bowel by double balloon enteroscopy. Dig Dis Sci. 2009;54(5):1050-8. https://doi.org/10.1007/s10620-008-0456-y.

38. Delle Fave G, O'Toole D, Sundin A, Taal B, Ferolla P, Ramage JK, et al. ENETS Consensus Guidelines Update for Gastroduodenal Neuroendocrine Neoplasms. Neuroendocrinology. 2016;103(2): 119-24. https://doi.org/10.1159/000443168.

39. Clift AK, Kidd M, Bodei L, Toumpanakis C, Baum RP, Oberg K, et al. Neuroendocrine neoplasms of the small bowel and pancreas. Neuroendocrinology. 2020;110(6):444-76. https://doi.org/10. 1159/000503721.

40. Frilling A, Smith G, Clift AK, Martin J. Capsule endoscopy to detect primary tumour site in metastatic neuroendocrine tumours. Dig Liver Dis. 2014;46(11):1038-42. https://doi.org/10.1016/j.dld. 2014.07.004.

41. Clift AK, Faiz O, Al-Nahhas A, Bockisch A, Liedke MO, Schloericke E, et al. Role of staging in patients with small intestinal neuroendocrine tumours. J Gastrointest Surg. 2016;20(1):180-8; discussion 8. https://doi.org/10.1007/s11605-015-2953-6.

42. Motz BM, Lorimer PD, Boselli D, Hill JS, Salo JC. Optimal lymphadenectomy in small bowel neuroendocrine tumors: analysis of the NCDB. J Gastrointest Surg. 2018;22(1):117-23. https://doi.org/10. 1007/s11605-017-3524-9 Small bowel NETs have high rates of nodal metastasis, even in patients with small tumors, and many patients do not undergo lymphadenectomy despite the clear benefit.

43. Koumarianou A, Alexandraki KI, Wallin G, Kaltsas G, Daskalakis $\mathrm{K}$. Pathogenesis and clinical management of mesenteric fibrosis in small intestinal neuroendocine neoplasms: a systematic review. J Clin Med. 2020;9(6). https://doi.org/10.3390/jcm9061777 Increased awareness and improved understanding of the molecular pathogenesis of mesenteric fibrosis in SI-NENs may provide better diagnostic and predictive tools for its timely recognition and intervention and also facilitate the development of agents targeting mesenteric fibrosis.

44. Klimstra D, Kloppel G, La Rosa S, Rindi G. Classification of neuroendocrine neoplasms of the digestive system in WHO Classification of Tumours - Digestive System Tumours. 5th Edition ed. Lyon: IARC Press; 2019. p. 20. Current WHOTNM classification (2019) of neuroendocrine neoplasms of the gastro-intestinal tract.

45. Jiang S, Zhao L, Xie C, Su H, Yan Y. Prognostic performance of different lymph node staging systems in patients with small bowel neuroendocrine tumors. Front Endocrinol (Lausanne). 2020;11: 402. https://doi.org/10.3389/fendo.2020.00402.

46. Chen L, Song Y, Zhang Y, Chen M, Chen J. Exploration of the exact prognostic significance of lymphatic metastasis in jejunoileal neuroendocrine tumors. Ann Surg Oncol. 2018;25(7):2067-74. https://doi.org/10.1245/s10434-018-6511-9.

47.• Ohrvall U, Eriksson B, Juhlin C, Karacagil S, Rastad J, Hellman P, et al. Method for dissection of mesenteric metastases in mid-gut carcinoid tumors. World J Surg. 2000;24(11):1402-8. https://doi. org/10.1007/s002680010232 Patients with advanced midgut carcinoids may benefit markedly from dissectional removal of mesenteric tumors.

48. Lardiere-Deguelte S, de Mestier L, Appere F, Vullierme MP, Zappa $\mathrm{M}$, Hoeffel C, et al. Toward a preoperative classification of lymph node metastases in patients with small intestinal neuroendocrine tumors in the era of intestinal-sparing surgery. Neuroendocrinology. 2016;103(5):552-9. https://doi.org/10.1159/ 000441423.

49.• Hallet J, Law C, Commonwealth Neuroendocrine Tumours Research Collaborative Surgical S. Extent of lymph node dissection for small bowel neuroendocrine tumors. World J Surg. 2020. doi:10.1007/s00268-020-05710-z. A mesenteric-sparing approach is favored to allow for resection for complex proximal nodal masses while preserving intestinal length and function.

50. Pasquer A, Walter T, Rousset P, Hervieu V, Forestier J, LombardBohas $\mathrm{C}$, et al. Lymphadenectomy during small bowel neuroendocrine tumor surgery: the concept of skip metastases. Ann Surg Oncol. 2016;23(Suppl 5):804-8. https://doi.org/10.1245/s10434016-5574-8.

51. Hellman P, Hessman O, Akerstrom G, Stalberg P, Hennings J, Bjorck M, et al. Stenting of the superior mesenteric vein in midgut carcinoid disease with large mesenteric masses. World J Surg. 2010;34(6):1373-9. https://doi.org/10.1007/s00268-009-0361-3.

52. Wright MF, Cates J, Gonzalez RS, Das S, Berlin JD, Shi C. Impact of peritoneal metastasis on survival of patients with small intestinal neuroendocrine tumor. Am J Surg Pathol. 2019;43(4):559-63. https://doi.org/10.1097/PAS.0000000000001225.

53. Frilling A, Li J, Malamutmann E, Schmid KW, Bockisch A, Broelsch CE. Treatment of liver metastases from neuroendocrine tumours in relation to the extent of hepatic disease. Br J Surg. 2009;96(2):175-84. https://doi.org/10.1002/bjs.6468 Staging of liver metatstasis within the liver and consequences for treatment.

54. Frilling A, Clift AK. Surgical approaches to the management of neuroendocrine liver metastases. Endocrinol Metab Clin N Am. 2018;47(3):627-43. https://doi.org/10.1016/j.ecl.2018.04.001.

55. Scharf M, Petry V, Daniel H, Rinke A, Gress TM. Bone metastases in patients with neuroendocrine neoplasm: frequency and clinical, therapeutic, and prognostic relevance. Neuroendocrinology. 2018;106(1):30-7. https://doi.org/10.1159/000457954.

56. Daskalakis K, Tsoli M, Srirajaskanthan R, Chatzellis E, Alexandraki K, Angelousi A, et al. Lung metastases in patients with well-differentiated gastroenteropancreatic neuroendocrine neoplasms: an appraisal of the validity of thoracic imaging surveillance. Neuroendocrinology. 2019;108(4):308-16. https://doi.org/ $10.1159 / 000497183$.

57. Ramage JK, De Herder WW, Delle Fave G, Ferolla P, Ferone D, Ito $\mathrm{T}$, et al. ENETS Consensus Guidelines Update for colorectal neuroendocrine neoplasms. Neuroendocrinology. 2016;103(2):139 43. https://doi.org/10.1159/000443166.

58. Sundin A, Arnold R, Baudin E, Cwikla JB, Eriksson B, Fanti S, et al. ENETS Consensus Guidelines for the Standards of Care in Neuroendocrine Tumors: radiological, nuclear medicine \& hybrid imaging. Neuroendocrinology. 2017;105(3):212-44. https://doi. org/10.1159/000471879.

59. Norlen O, Montan H, Hellman P, Stalberg P, Sundin A. Preoperative (68)Ga-DOTA-somatostatin analog-PET/CT hybrid imaging Increases detection rate of intra-abdominal small intestinal neuroendocrine tumor lesions. World J Surg. 2018;42(2):498-505. https://doi.org/10.1007/s00268-017-4364-1. 
60.• Bertani E, Falconi M, Grana C, Botteri E, Chiappa A, Misitano P, et al. Small intestinal neuroendocrine tumors with liver metastases and resection of the primary: prognostic factors for decision making. Int J Surg. 2015;20:58-64. https://doi.org/10.1016/j.ijsu.2015. 06.019 The Ki-67 index, the liver tumor burden and the presence of extrahepatic metastases should be carefully considered in the selection criteria for liver debulking in asymptomatic patients.

61. Partelli S, Bartsch DK, Capdevila J, Chen J, Knigge U, Niederle B, et al. ENETS Consensus Guidelines for Standard of Care in Neuroendocrine Tumours: surgery for small intestinal and pancreatic neuroendocrine tumours. Neuroendocrinology. 2017;105(3): 255-65. https://doi.org/10.1159/000464292.

62. Moris D, Ntanasis-Stathopoulos I, Tsilimigras DI, Vagios S, Karamitros A, Karaolanis G, et al. Update on Surgical Management of Small Bowel Neuroendocrine Tumors. Anticancer Res. 2018;38(3):1267-78. https://doi.org/10.21873/ anticanres.12349.

63. Shah MH, Goldner WS, Halfdanarson TR, Bergsland E, Berlin JD, Halperin D, et al. NCCN Guidelines Insights: neuroendocrine and adrenal tumors, Version 2.2018. J Natl Compr Cancer Netw. 2018;16(6):693-702. https://doi.org/10.6004/jnccn.2018.0056.

64. Strosberg JR, Halfdanarson TR, Bellizzi AM, Chan JA, Dillon JS, Heaney AP, et al. The North American Neuroendocrine Tumor Society Consensus Guidelines for Surveillance and medical management of midgut neuroendocrine tumors. Pancreas. 2017;46(6): 707-14. https://doi.org/10.1097/MPA.0000000000000850.

65.• Hallet J, Law C. Commonwealth Neuroendocrine Tumours Research Collaborative Surgical S. Role of primary tumor resection for metastatic small bowel neuroendocrine tumors. World $\mathrm{J}$ Surg. 2020. https://doi.org/10.1007/s00268-020-05727-4 All patients with stage IV SB-NETs should be assessed by a surgeon experienced in the managementof NETs to consider surgical therapies, including resection of the primary tumor despite metastatic disease.

66. Kim MK, Warner RR, Ward SC, Harpaz N, Roayaie S, Schwartz $\mathrm{ME}$, et al. Prognostic significance of lymph node metastases in small intestinal neuroendocrine tumors. Neuroendocrinology. 2015;101(1):58-65. https://doi.org/10.1159/000371807 The extent of $\mathrm{LN}$ involvement provides independent prognostic information on patients with LN-positive SI-NETs. This information may be used to identify patients at high risk of recurrence and inform decisions about the use of adjuvant therapy.

67. Daskalakis K, Karakatsanis A, Hessman O, Stuart HC, Welin S, Tiensuu Janson E, et al. Association of a prophylactic surgical approach to stage IV small intestinal neuroendocrine tumors with survival. JAMA Oncol. 2018;4(2):183-9. https://doi.org/10.1001/ jamaoncol.2017.3326 Prophylactic up-front locoregional surgery conferred no survival advantage in asymptomatic patients with stage IV SI-NETs. Delayed surgery as needed was comparable in all examined outcomes and was associated with fewer reoperations for intestinal obstruction. The value of a priori locoregional surgery in the presence of distant metastases is challenged and needs to be elucidated in a randomized clinical study.

68. Bagante F, Spolverato G, Merath K, Postlewait LM, Poultsides GA, Mullen MG, et al. Neuroendocrine liver metastasis: the chance to be cured after liver surgery. J Surg Oncol. 2017;115(6):687-95. https://doi.org/10.1002/jso.24563.

69. Gaujoux S, Gonen M, Tang L, Klimstra D, Brennan MF, D'Angelica M, et al. Synchronous resection of primary and liver metastases for neuroendocrine tumors. Ann Surg Oncol. 2012;19(13):4270-7. https://doi.org/10.1245/s10434-012-2462-8.

70. Glazer ES, Tseng JF, Al-Refaie W, Solorzano CC, Liu P, Willborn $\mathrm{KA}$, et al. Long-term survival after surgical management of neuroendocrine hepatic metastases. HPB (Oxford). 2010;12(6):427-33. https://doi.org/10.1111/j.1477-2574.2010.00198.x.

71. Mayo SC, de Jong MC, Bloomston M, Pulitano C, Clary BM, Reddy SK, et al. Surgery versus intra-arterial therapy for neuroendocrine liver metastasis: a multicenter international analysis. Ann Surg Oncol. 2011;18(13):3657-65. https://doi.org/10.1245/ s10434-011-1832-y.

72. Mayo SC, de Jong MC, Pulitano C, Clary BM, Reddy SK, Gamblin TC, et al. Surgical management of hepatic neuroendocrine tumor metastasis: results from an international multi-institutional analysis. Ann Surg Oncol. 2010;17(12):3129-36. https://doi.org/10.1245/ s10434-010-1154-5.

73. Saxena A, Chua TC, Sarkar A, Chu F, Liauw W, Zhao J, et al. Progression and survival results after radical hepatic metastasectomy of indolent advanced neuroendocrine neoplasms (NENs) supports an aggressive surgical approach. Surgery. 2011;149(2):209-20. https://doi.org/10.1016/j.surg.2010.06.008.

74. Manguso N, Nissen N, Hendifar A, Harit A, Mirocha J, Friedman $\mathrm{M}$, et al. Prognostic factors influencing survival in small bowel neuroendocrine tumor with liver metastases. J Surg Oncol. 2019;120(6):926-31. https://doi.org/10.1002/jso.25657 The extent of resection of liver disease in SBNET influenced survival at 5 years but not at 10 years. In addition, more than 10 liver lesions and chemotherapy were predictors of mortality.

75.• Rindi G, Kloppel G, Alhman H, Caplin M, Couvelard A, de Herder WW, et al. TNM staging of foregut (neuro)endocrine tumors: a consensus proposal including a grading system. Virchows Arch. 2006;449(4):395-401. https://doi.org/10.1007/s00428-006-0250-1 ENETS proposal for a working formulation for the grading of digestive NETs based on mitotic count and Ki-67 index.

76.• Rindi G, Kloppel G, Couvelard A, Komminoth P, Korner M, Lopes $\mathrm{JM}$, et al. TNM staging of midgut and hindgut (neuro) endocrine tumors: a consensus proposal including a grading system. Virchows Arch. 2007;451(4):757-62. https://doi.org/10.1007/s00428-0070452-1 The ENETS TNM classifications for NETs of the ileum, appendix, colon and rectum, and the grading system were designed, discussed and consensually approved.

Publisher's Note Springer Nature remains neutral with regard to jurisdictional claims in published maps and institutional affiliations. 